C2004 IEEE. Personal use of this material is permitted. However, permission to reprint/republish this material for

advertising or promotional purposes or for creating new collective works for resale or redistribution to servers or lists,

or to reuse any copyrighted component of this work in other works must be obtained from the IEEE. 


\title{
Monitoring and Charge-Control of Lead-Acid Batteries in Photovoltaic Applications
}

\author{
Cesar Ortega, Jaime Orozco, Jojutla Pacheco and Alejandro Rivera \\ Inst. of Electrical Research / Dept. of Control and Instrumentation \\ Cuernavaca, MEXICO \\ ortegas@iie.org.mx
}

\begin{abstract}
This paper presents a microcontroller-based charge controller suitable for photovoltaic applications. The controller performs temperature-compensated charge control. It also monitors and stores those parameters that provide an indication of batteries' state of charge and state of health: Panel's voltage, battery's voltage and current, current demanded by a load and temperature.

The controller has serial communication capabilities that make possible the interface to a personal computer or central station. By using a local industrial network or remote links via radio, multiple remote controllers can be monitored by a central station running a battery management program. The information collected from all the controllers in the system is analyzed to determine the state of charge of individual batteries and, if required, command the appropriate controller to perform special procedures like, for example, thorough diagnostics or equalization. Preliminary field-test results of a controller installed in a high-way emergency bay are presented in the paper. It is shown that protection against deep discharges is achieved, which contributes to extend the battery useful life.
\end{abstract}

\section{INTRODUCTION}

Accurate charge control and state of charge monitoring of lead-acid batteries (LABs) is an ever-increasing necessity in an industry that demands low-maintenance costs and highly available systems. If the batteries are charged by photovoltaic panels (PVPs), and are installed in remote sites (e.g. Oil seaplatforms, highway emergency bays, communication systems) and exposed to aggressive environmental conditions (e.g. Extreme temperature, high humidity), the problem of extending the batteries' useful life becomes a challenge. Most charging algorithms do not perform well when PVPs are the sole source of energy because energy availability is not guaranteed. A charging algorithm that exploits to the maximum the energy generated by the panel during sunny hours is needed.

Charge-controllers are electronic devices that keep the LABs operating within their safety limits. Typically, chargecontrollers protect the LABs by disconnecting the energy source when the batteries have reached $100 \%$ of their charge capacity and by disconnecting the load when the state-ofcharge (SOC) has reached a lower limit. Charge-control of LABs is a difficult and much researched topic $[1,2,3,4,5]$. The problem becomes more complicated when the sole energy source of the system is a photovoltaic panel [6]. In this case, the energy supply is non-constant and non-predictable.
Performance of LABs is extremely dependant on the temperature of operation. The voltage applied during the charge cycle must be adjusted for temperature if the useful life of LABs is to be maximized. A charge-controller capable of adapting to the operational conditions of each particular application (including temperature compensation) will protect the battery while using it-to the extent of its capabilities.

This paper presents a LABs charge-controller intended for photovoltaic applications. The charge-controller performs continuous monitoring of batteries' SOC and other operational parameters in order to fine-tune the charge algorithm. It also has the capability of transmitting the collected data to a remote central station, where it can be analyzed. The charge-controller is being developed at the Control and Instrumentation Department (GCI) of the Institute of Electrical Research (IIE), Mexico.

\section{SYSTEM DESCRIPTION}

Figure 1 shows the two main components of the chargecontrol system: a central station implemented in a personal computer and one or several remote stations.

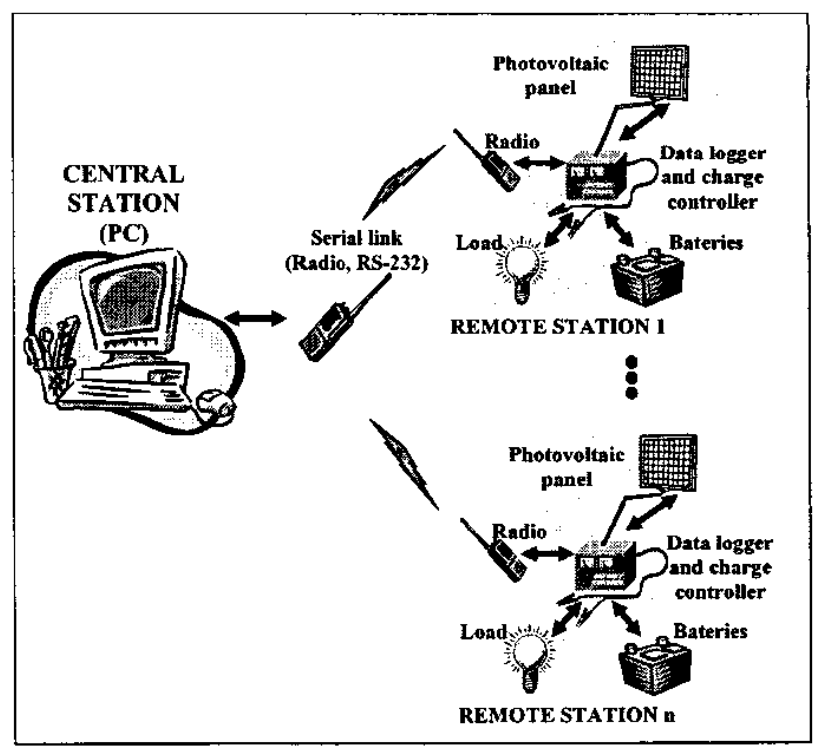

Fig. 1. System architecture 
The central station collects and analyses the data provided by every remote station in the system. Remote stations perform LAB charge-control, monitor the main electrical parameters along with the temperature, and send this information to the central station. The central and remote stations exchange information by means of a serial communication channel. In the example shown in figure 1 this channel is a short-range radio link however, other serial communication media can be used, e.g. an RS -485 network.

In conventional charge-controllers, all decisions are taken based on local information and control actions are limited to the ones pre-programmed in the controller. There is no flexibility to allow dynamic adaptation. With remote monitoring it is possible to adapt the control to both local (temperature, irradiance, electrical parameters) and historic (charge and discharge profiles, statistical analysis of collected data) conditions. In the IIE system, parameters that define the charge algorithm in a particular remote station can be remotely modified by the central station. It is expected that this adaptability will improve the useful life of lead-acid batteries. System security can also be improved by using remote monitoring. It is possible to use the communication channel to send an emergency signal when a non-authorized access is detected [7].

A remote station can also work stand-alone without implementing the monitoring functions and performing only the charge-controller functions. In this case, parameters and set points of the charge algorithm must be set before installation. This operational mode is suitable for applications lacking a communications network.

In its present stage, the controller controls currents of up to $15 \mathrm{~A}$ and voltages from 6 to $24 \mathrm{~V}$. The power stage is being revised so that higher currents can be handled.

\section{CENTRAL Station PROGRAM}

The central station runs a data analysis program that has been developed using LabViewß from National Instruments ${ }^{\mathrm{TM}}$. In its present stage the central station program stores, analyzes and displays data collected from the remote stations. An experienced system administrator can infer a great deal of information through observation of historic variations in the graphs of the system's electrical parameters. To simplify this task, voltages, currents, temperature and SOC are all presented in the same graph. The user can select the parameters to be shown, and graphs are easily zoomed in and out allowing the visual inspection of small details.

Figure 2 shows the graphs corresponding to the slowcharge-cycle of a battery. For this experiment, the battery was charged in the laboratory using a switching power supply. It is shown that the time required to take the battery from $35 \%$ to $98 \%$ state-of-charge (SOC) was approximately 10 days. The battery stopped accepting current on day 15 . At this point it is considered that the battery has reached its $100 \%$ SOC. The slow-charge-cycle is achieved by limiting the current to 4.0 Amperes at the beginning of the cycle by means of a PWM control algorithm running in the controller.

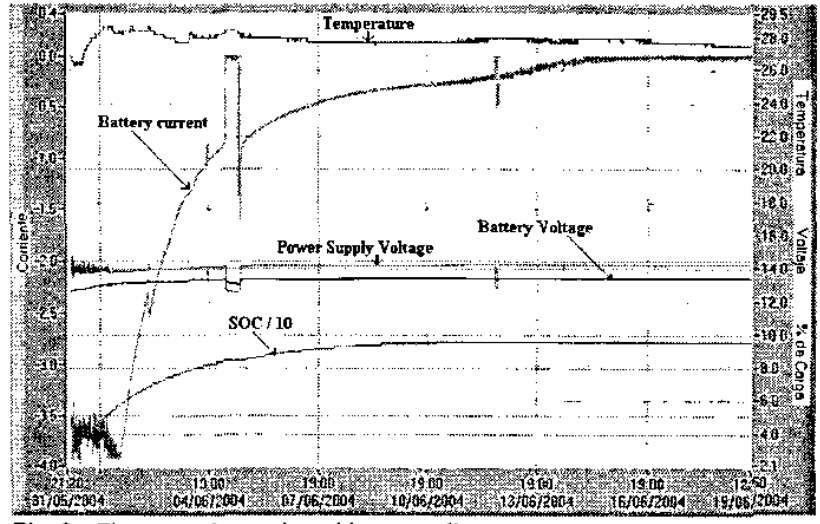

Fig. 2. Charge-cycle monitored by controller

Note in figure 2 that temperature stayed almost constant throughout the charging operation. Contrast this graph against the temperature registered in a field application, show in figure 6 .

Figure 3 shows a detail of the slow-charge-cycle in figure 2. On the $5^{\text {th }}$ of June, there was a blackout in the laboratory. Hence, the power supply was off-line and the current supplied to the battery went to zero. After the power supply was reset, the charge continued uneventfully.

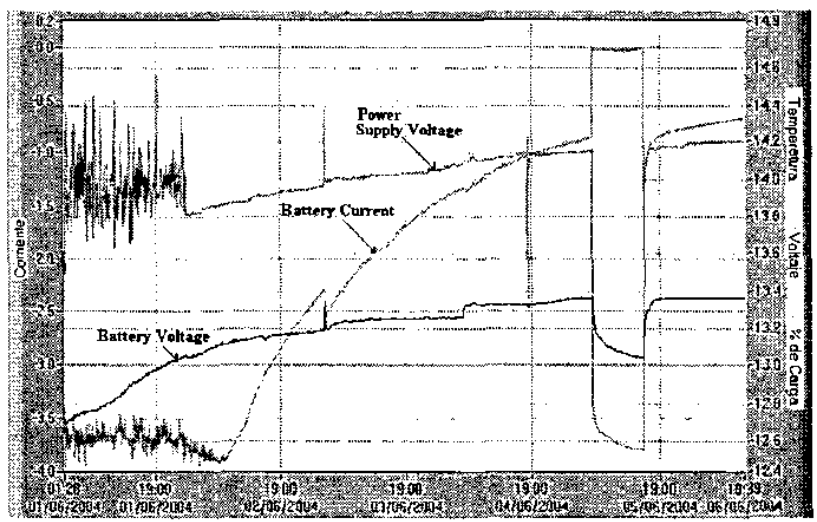

Fig. 3. Detail of the charge-cycle graph in figure 2 .

\section{CONTROLLER ARCHITECTURE}

Figure 4 shows the block diagram of the charge-controller. The architecture is based on a microcontroller that reliably performs analogue acquisition and communications. There are in the market low-power microcontrollers that integrate most of the analogue and digital blocks shown in figure 4 . The analogue channels are used to monitor voltages, currents and temperature of the system. The controller takes its power from the battery that is being monitored.

The charge control algorithm is performed by the microcontroller, therefore it is possible to modify the controller set points and even change the algorithm itself. This characteristic allows to fine-tune the charge control algorithm so that it can cope with the operational conditions particular to each remote station. In the case of photovoltaic applications, the charging-algorithm is modified so that the 
current supplied to the battery is never limited. The strategy is to provide the battery with as much current as possible during sunlight-hours because it is not known when the following opportunity to do so is going to happen. Besides, the maximum current that a photovoltaic panel can provide on a typical small application is not large enough to provoke permanent damage to a $\mathrm{LAB}$.

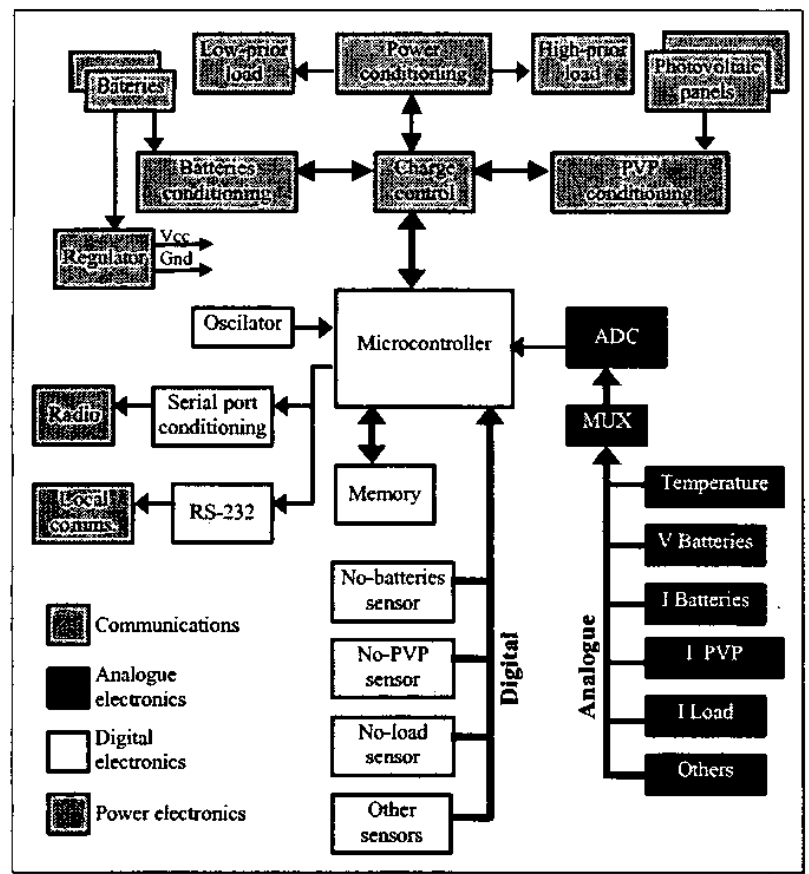

Fig. 4. Block diagram of the charge-controller.

Batteries deliver their charge through the controller to two different kinds of loads: High-priority loads and low-priority loads. If batteries are discharged below a predefined threshold, then the low-priority loads will be disconnected from the system so that the remaining charge can be used by high-priority loads. When this situation arises, a notification is sent to the central station. There are several conditions that could provoke batteries to reach their low-charge threshold; for example, several cloudy days in a row (low irradiance), a charge demand higher than average, due to either a failure or excess of use; a failure in the photovoltaic panels or end of batteries useful life.

Since the remote stations are usually installed in isolated sites (e.g. unmanned oil sea-platforms, highway emergency bays), they can perform some diagnostics by means of local sensors and programs. Also, the central station can initiate a diagnosis operation to detect the presence of critical elements in the system (batteries, PVP, load). Remote diagnosis reduces in situ checks and maintenance of remote stations.

\section{FIELD-TESTS RESULTS}

The first prototype of the controller was installed in an highway emergency bay near Cuernavaca City, Mexico. Figure 5 shows the photograph of the equipment typically found in an emergency bay (batteries, radio, chargecontroller, photovoltaic panel).

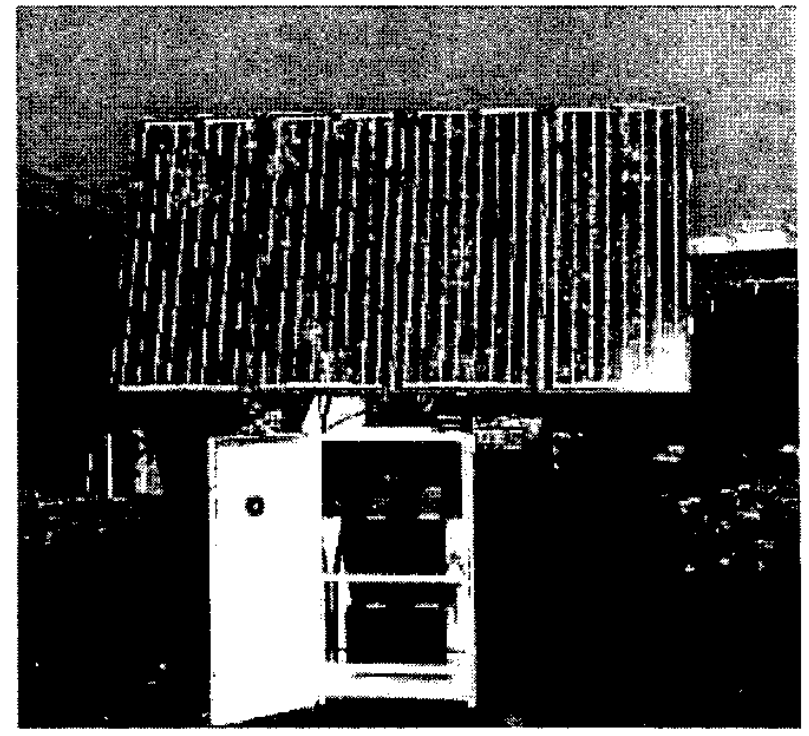

Fig. 5. Typical equipment in a highway emergency bay.

The controller has been monitoring the behavior of the system since September, 2003. Figure 6 shows the graphs corresponding to the first five months of 2004.

By observing the graphs in figure 6 it is possible to find the overall trends of the variables. Temperature increased as the year advanced, being April the hottest month of the year in Cuernavaca. The current injected to the battery (negative values in the graph), also increased as temperature raised. There is a clear correlation between temperature (irradiance) and current supplied by the PVP. According to these two graphs, the batteries should have been better charged as the year advanced however, the graph of SOC indicates a gradual reduction in the batteries capability to accept current. This behavior indicates that either the battery needs maintenance, or it has reached its useful life and needs to be replaced.

Data obtained from monitoring can be used to determine other parameters of the system such as the number of hours per day that the radio is disconnected from the battery or the daily average of temperature and electrical parameters. Figure 7 shows an example of such graphs.

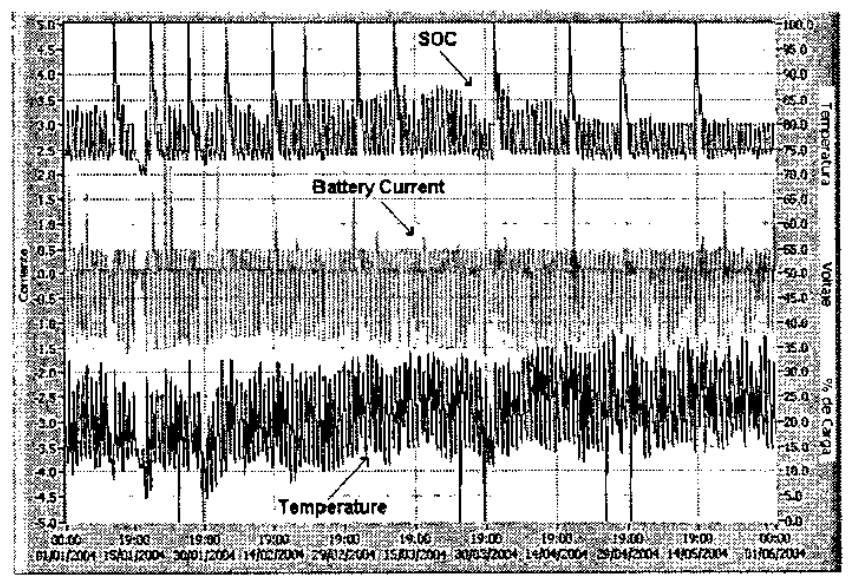

Fig. 6. Five-months monitoring of an emergency bay. 


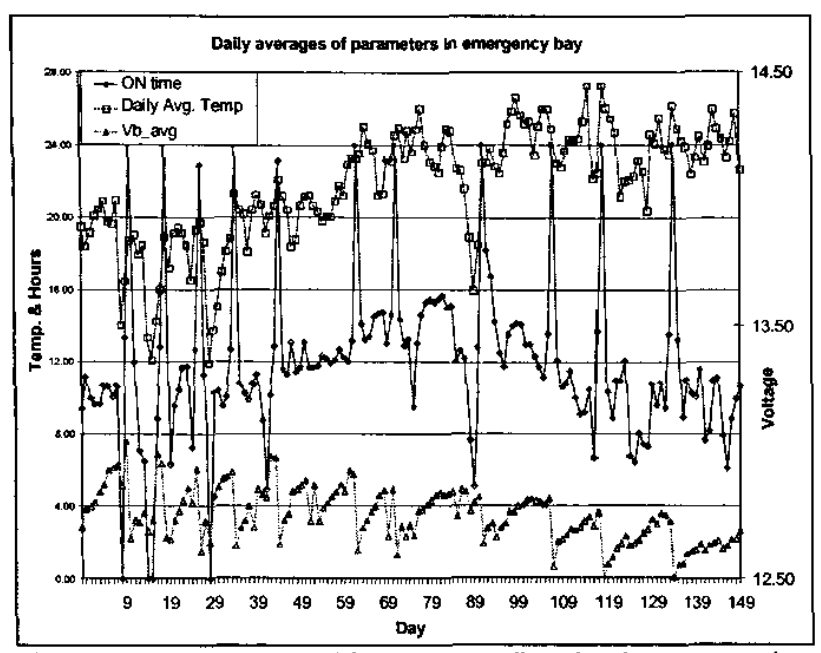

Fig. 7. Some graphs generated from the data collected at the emergency bay.

In figure 7 , the "ON-time" graph shows the number of hours per day that the radio was connected to the battery. During the five-months period, the radio was available the 24hours only in 9 days. Most of the days the radio was available between 10 and 14 hours, and there were three days at the beginning of the year (the cold season) where there was no radio at all. These three days match with the lowest temperatures registered.

The "Daily Avg. Temp." graph shows an steady increase in average temperature as the year advanced. The lowtemperature peaks correspond to very cloudy days when the levels of solar irradiance were minimum.

The " $V_{b \_} a v g$ " graph shows an steady fall in voltage even though the current injected into the battery increased as temperatures raised. This again, is an indication of the battery needing immediate maintenance or replacement.

\section{CONCLUSIONS AND FUTURE WORK}

The description of a system to perform charge-control of lead-acid batteries in photovoltaic applications has been presented. The main components of the systems are a central station and one or more remote stations. Every remote station in the system controls the charging of a LAB whose power supply is a PVP. The data gathered on every remote station can be transmitted to a central station where they are stored, analyzed and displayed by a battery management program. As data accumulates for each battery in the system, an experienced system administrator can estimate parameters such as state of health and remaining useful life per battery.

Due to its programmability, the remote station can be used as a test-bench for self-adaptable charge-control algorithms. Work is being done on the estimation of SOC by means of artificial neural networks. Promising results have been obtained so far.
A long-term goal of this project is to have an intelligent charge-controller with the ability to adapt to the charge/discharge behavior of a particular battery, taking into account temperature compensation and its historic trends.

Another potential application of the remote station is as stand-alone test-bench to characterize lead-acid batteries subject to different charge-control algorithms. In conjunction with the central station's battery-management program, a powerful system for data-logging and analysis can be achieved.

Future developments at the Department of Control and Instrumentation will incorporate the experiences acquired in the field of stand-alone photovoltaic systems. This is an area that promise to expand in the following years, mainly in underdeveloped countries where rural electrification is increasingly relying on non-conventional power sources.

\section{ACKNOWLEDGEMENTS}

The authors wish to thank the Institute of Electrical Research for supporting this work and the Bureau of Mexican Roads and Highways (CAPUFE) for the support given in performing field-tests to the controller.

\section{REFERENCES}

[1] Alzieu J. Smimite H. and Glaize C., "Improvement of intelligent battery controller: state-of-charge indicator and associated functions", J. of Power Sources, Vol.67, 1997, pp. 157-161

[2] Catherino H., Burgel J., Rusek A. and Feres F., "Modelling and simulation of lead-acid battery charging", $J$. of Power Sources, Vol.80, 1999, pp.17-20

[3] Copetti J. and Chenlo F., "Lead/acid batteries for photovoltaic applications. Test results and modeling", J. of Power Sources, Vol.47, 1994, pp.109-118

[4] Fleming F., Shumard P. and Dickinson B., "Rapid recharge capability of valve-regulated lead-acid batteries for electric vehicle and hybrid electric vehicle applications", $\underline{\mathbf{J} \text {. of Power }}$ Sources, Vol.78, 1999, pp.237-243

[5] Huacuz J. and Urnutia M. (Eds.), Controladores de carga para sistemas fotovoltaicos de elctrificación rural, Taller RIER-IIE, Instituto de Investigaciones Eléctricas, Cuernavaca, México, Julio 1998.

[6] Urbina A., Paez T., O'Gorman C., Barney P., Jungst R and Ingersoll D., "Reliability of rechargeable batteries in a photovoltaic power supply system", J. of Power Sources, Vol.80, 1999, pp.30-38

[7] Ortega C., Orozco J., Pacheco J., Cristín M. and Rivera A., "Charge-Control of Lead-Acid Batteries in Photovoltaic Applications", Proceedings of ISEC 2004, ASME International Solar Energy Conference, July 11-14, 2004Portland, Oregon, USA. 